\title{
SEMANTIC COMPONENTS OF THE RUSSIAN PREPOSITION “UEPE3” IN COMBINATION WITH DIFFERENT LOCUMS AND ITS EXPRESSION IN THE PERSIAN LANGUAGE
}

\author{
M. Estiri, Kh. Torkashvand \\ Gonbad Kavous university, \\ 4971799151, Iran, Golestan, Gonbad Kavus, st. Falahi, Basirat Blvd.
}

\begin{abstract}
In the Russian language the preposition "cherez (through)" is used in its typical contexts to refer to spatial characteristics in which an action or movement takes place. However, there are cases in the Persian language when there is no clear boundary among the spatial prepositions corresponding to the preposition "cherez (through)", which causes difficulty for Iranian learners to choose the correct one. At the same time one and the same Persian preposition can be expressed by different Russian prepositions which lead to regular mistakes in the speech of Iranian students. Thus, for instance, Iranian students use the preposition "az miyan-e" / (among) in the meaning of the Russian prepositions "cherez" (through), "mezhdu", "ckvoz" (within) and "iz" (from), although these prepositions are different in meaning and function. In this article, the locations used in combination with the preposition "through" are systematically classified to explain their specific features. In addition, the ways of expressing the spatial meanings of the preposition "through" in the Persian language are addressed in order to raise Iranian learners' awareness of possible mistakes. The novelty of the article is in the attempt to compare semantic and spatial features of the Russian preposition "cherez (through)" with its correlates in the Persian language. The findings of this study can be of interest to RFL teachers, in particular in Iran, as they will highlight common mistakes in the speech of Iranian learners when using the preposition "through", and to RFL textbook developers.
\end{abstract}

Key Words: spatial relations, space, route of movement, object, preposition "cherez (through)", locum, the Russian language, the Persian language

For citation: M. Estiri, Kh. Torkashvand (2021). Semantic Components of the Russian Preposition "Yерез" in Combination With Different Locums and its Expression in the Persian Language. Philology at MGIMO, 7(3), pp. 43-52. https://doi.org/10.24833/2410-2423-2021-3-27-43-52 


\title{
СЕМАНТИЧЕСКИЕ КОМПОНЕНТЫ ПРЕДЛОГА «ЧЕРЕЗ" В СОЧЕТАНИИ С РАЗНЫМИ ЛОКУМАМИ И СПОСОБЫ ЕГО ВЫРАЖЕНИЯ В ПЕРСИДСКОМ ЯЗЫКЕ
}

\author{
М. Эстири, Х. Торкашванд \\ Университет Гонбад-Кавус, \\ 4971799151, Иран, Голестан, г. Гонбад-Кавус, ул. Фалахи, конец бульвара Басират.
}

\begin{abstract}
Аннотация. В русском языке предлог «через» употребляется в характерных для него ситуациях и конкретизирует характеристику локума, в котором происходит действие или движение. Однако есть случаи, когда в персидском языке отсутствует чёткая граница между значениями пространственных предлогов, соответствующих предлогу «через», и это вызывает ошибки у иранских обучающихся при выборе правильного пространственного предлога. С другой стороньь, один и тот же персидский предлог способен выражаться разными русскими предлогами, употребление которых в речи иранских студентов сопровождается своеобразными и достаточно устойчивыми очибками. Так, иранские обучающиеся употребляют предлог аz тіуап-е в значении предлогов через, между, сквозь и из, в то время как семантика указанных предлогов и их употребление отличаются большим своеобразием. В статье систематизируются локумы в сочетании с предлогом "через», трактуется их специфика, изучаются способы выражения пространственных значений предлога «через» в персидском языке с иелью способствовать осознанному усвоению пространственных средств с предлогом «через» у иранских обучающихся. Новизна статьи заключается в том, что впервые в иранской русистике предлог "через» сопоставляется со своими коррелятами в персидском языке по семантическим и пространственным особенностям. Результаты могут быть использованы в практике преподавания русского языка в иноязычной среде, в частности в Иране, с иелью дальнейшей нейтрализации ошибок при употреблении предлога «через», а также методистами при составлении учебников и пособий по русскому языку как иностранному.

Ключевые слова: пространственные отночения, пространство, трасса движения, объект, предлог «через», локум, русский язык, персидский язык
\end{abstract}

Для цитирования: Эстири М., Торкашванд Х., (2021). Семантические компоненты предлога «через» в сочетании с разными локумами и способы его выражения в персидском языке. Филологические науки в МГИМО. 7(3), С. 43-52. https://doi.org/10.24833/2410-2423-2021-3-27-43-52

Ч тобы полностью понять семантические компоненты предлога «через» в сочетании с разными локумами, прежде всего нужно разобраться в определении и свойствах пространства. Пространство - это категория, отражающая местонахождение, расположение и форму материальных явлений и предметов. Категория пространства рассматривается в разных науках. Так, применительно к лингвистике пространство можно рассматривать как категорию, отражающую местонахождение (зону, участок) каких-либо объектов действительности относительно субъекта, вступающего с ними в субъектно-объектные отношения, или относительно друг друга (объектно-объектные отношения), а также как характеристику расстояния между ними (протяжённость, даль, близь) [5]. Категория пространства выражается пространственными от- 
ношениями. Под пространственными отношениями понимаются различные положения лиц или предметов относительно друг друга [10, с. 150].

Пространственные отношения - это отношения, которые связывают позиционируемый объект и локум. Пространственные отношения уточняются спецификой локума и положением объекта относительно локума. Локум - пространство, предмет, лицо, представляемые как ориентир, относительно которого характеризуется локализуемый объект [4, с. 282]. Локализуемым объектом может быть предмет, лицо, событие, явление и т.п. [Там же]. По определению М.В. Всеволодовой и Е.Ю. Владимирского локум - трасса движения, составляя часть пути движения, входит в него целиком [3, с. 126]. Также, по их мнению, в значении локума содержатся два нюанса: а) локум - путь сообщения; б) локум - преодолеваемое пространство [Там же]. Кроме того, на взгляд авторов статьи, локум может быть препятствием или сопредельным пространством.

В русском языке пространственные отношения выражаются разнообразными способами:

1) морфологическим средством (существительное в косвенном падеже без предлога: Дорога шла сосновым лесом;

2) лексическим средством (наречие, которое выражает пространственное значение: Домик снаружи покрасили голубой краской;

3) синтаксическим средством: а) предлог в сочетании с существительным или местоимением в косвенном падеже: Мы шли через лес. б) сложноподчинённое предложение с пространственным значением: Я ходил в кино, где показывали фильм.

Наиболее употребительным грамматическим средством со значением пространственных отношений является синтаксическое средство, то есть сочетание предлогов с падежными формами имён существительных или местоимений.

В персидском языке категории падежа и рода отсутствуют, и пространственные отношения выражаются наречиями и предлогами в сочетании с существительными или местоимениями. Не изменяясь и не являясь членами предложения, в русском и персидском языках предлоги выражают разные отношения, включая пространственные. В русском языке пространственные предлоги существуют во всех падежах, кроме именительного. Сравнить систему средств выражения пространственных отношений между персидским и русским языками невозможно, потому что русский язык является типичным флективным языком, а персидский - аналитическим, то есть формы слов в различных ситуациях употребления остаются неизменными. Кроме того, в зависимости от системы родного языка каждый воспринимает локум по-своему и выражает его разнообразными способами. Помимо отсутствия падежной системы в персидском языке, наблюдается и отсутствие однозначного межъязыкового соответствия между русскими и персидскими предлогами. Так, предлог az miyan-е соответствует русским предлогам через, между, сквозь и из, а предлоги az dakhel-e, az vasat-e, az beyn-e, az miyan-e, az, az tarigh-e, az ru-ye, az faraz-e - русскому через.

Следует отметить, что в существующих грамматиках персидского языка семантические особенности предлогов специально не рассматриваются. Иначе говоря, из-за ограничений, связанных с аналитическим строем персидского языка и отсутствием в нём падежей, иранским лингвистам не удалось всесторонне раскрыть все значения многих из персидских предлогов. С другой стороны, значения, данные в двуязычных словарях, не всегда дают возможности установить и сопоставить семантические различия между синонимичными предлогами, в частности через и сквозь. В русско-персидских словарях Г.А. Восканяна [2] и И.К. Овчинниковой [6] предлог «через» в значении пространственных отношений выражен предлогами az, az miyan-e, az ru-ye, ru-ye, az faraz-e, az bala-ye, az vasat-e, az tarigh-e, az rah-e.

Как в русском, так и в персидском языке предлоги как служебные слова классифицируются по-разному. В русском языке предлоги разделяются по строению на непроизводные, или первообразные, (через, сквозь, без, кроме, между и т.д.) и производные, или непервообразные, (вдоль, благодаря, не смотря на, вблизи и т.д.), по значению - на пространственные (через, сквозь, в, на, у, около и др.), временные (до, через, в, на, перед, в течение и др.), причинные (от, со зла, за, из-за, в силу, по случаю, благодаря и др.), целевые (в, по, к, за, для, ради и др.), образ действия (c, без, в, от u др.) и объективные (o, про, c, по, насчёm, относительно и др.), по структуре - на простые (через, 
сквозь, мимо, путём и др.), сложные (из-за, из-под и др.) и составные (в отличие от, по отноче-

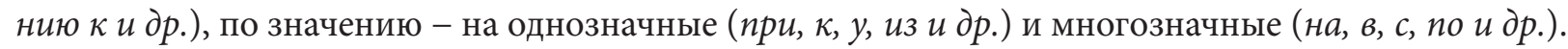

В персидском языке Ю.А. Рубинчик разделяет предлоги по своему происхождению на первичные (собственно предлоги, основные предлоги) и вторичные (производные, отыменные, изафетные) [7, с. 311]. Вторичные предлоги часто сочетаются с первичными предлогами: az miyan-e, az dakhel-e, az vasat-e и т.п.

Кроме того, на основе классификации таких иранских грамматистов, как Х. Фаршидвард [15], Х. Ахмади-Гиви и Х. Анвари [11], персидские предлоги бывают простые и сложные в зависимости от их состава. Простые предлоги состоят из одного слова (az-через, сквозь, из, om, y; бэ - в, на, $\kappa)$, сложные - из двух слов (az miyan-e - через, из, сквозь, между, no; ghabl az - к, перед, до), а иногда - из трёх (be gheyr az-кроме).

Ряд современных ведущих грамматистов персидского языка, такие как Х. Хатиб-Рахбар [12], М.Дж. Шариат [14], А. Хаямпур [13] и др., рассматривали персидские предлоги с точки зрения семантики.

На основании приведённых вышеуказанными авторами толкований предлог az miyan-e в зависимости от контекста может обозначать направление движения и действия из внутренней стороны, части локума к наружной. В этом же значении можно употреблять и предлог az dakhel-e, являющийся синонимом к предлогу az miyan-e, но в русско-персидских словарях Г. А. Восканяна [2] и И. К. Овчинниковой [6] он не указан как коррелят предлога «через». Предлоги az dakhel-e и az miyan-e относятся к нейтральному стилю речи. Предлоги az miyan-e, az vasat-e и az beyn-e выражают направление движения и действия через центр, по центру, а не по периферии локума. В персидском языке данные предлоги отличаются друг от друга не значением, а стилистикой. Предлог az-miyan-e свойствен книжному стилю речи, а предлоги az vasat-e и az beyn-e - нейтральному. Предлоги $a z$ ru-ye, az bala-ye и az faraz-e указывают на направление движения или действия контактно по поверхности локума или поверх его верхней границы. Предлоги az ru-ye и az bala-ye используются в нейтральном стиле, а предлог az faraz-e - в книжном. Предлоги az tarigh-e и $a z$ rah-e указывают на трассу движения или локума, через которые преодолевается локум или достигается какая-то цель. Предлог az tarigh-е относится к книжному стилю речи, а предлог $a z$ rah-e - к нейтральному. Предлог az arz-e, который соответствует предлогу «через» и значение которого не указано в русско-персидских словарях, выражает перемещение или движение, которое совершается поперёк локума (с одной стороны локума на другую сторону), а не вдоль него. Этот предлог употребляется в нейтральном стиле речи. Предлог az относится к нейтральному стилю речи и его нередко можно заменить любым из вышеуказанных предлогов.

B «Словаре русского языка в четырёх томах» под редакцией А.П. Евгеньевой [8] указано тринадцать значений предлога «через», из которых семь значений сосредоточены на пространственных отношениях, а в «Словаре современного русского литературного языка» [9] приведены десять общих значений предлога «через», пять из которых являются пространственными.

Предлог «через» употребляется для выражения специфического характера движения и перемещения в локуме. Он показывает данный специфический характер перемещения структурой чере + B.n. в сочетании с приставочными и бесприставочными глаголами движения, а также глаголами зрительного и слухового восприятия и воздействия. Ниже перейдём к рассмотрению семантических компонентов предлога «через» в различных локумах и способам его выражения в персидском языке.

Предлог «через» является простым, непроизводным (первообразным) и употребляется только с винительным падежом (однозначным). На взгляд Е.Ю. Владимирского, главное значение предлога «через» в сочетании с существительными в винительном падеже - пересечение и преодоление какого-либо локума, чаще по его поверхности [1].

$\mathrm{B}$ «Книге по грамматике» под редакцией А.В. Величко указано, что этот предлог подчёркивает однонаправленность движения, подразумевает достижение конца локума (движение из конца в конец) $[4$, с. 304]. В этой книге локум в сочетании с предлогом «через» рассматривается с двух аспектов: с одной стороны, локум и его протяжённость преодолевается без трудностей, с другой 
стороны, локум, по (на) поверхности которого существуют препятствия, преодолевается с физическими трудностями [4].

В зависимости от разновидности локума и характера перемещения употребляются разные семантические компоненты предлога «через», которые перечислены ниже:

1. Предлог «через» в сочетании с существительными брод, переход, туннель, канал, пролив, коридор, переулок, труба, ущелье и т.п. демонстрирует сооружённый или природный путь с ограниченной шириной и незначительной протяжённостью, соединяющий два локума [1], [4]. В этой особой позиции локум составляет часть общего пути. Предлог «через» в сочетании с данными локумами может описывать путь движения, который протягивается в направлении длины локума. Наиболее ясно это значение выявляется при глаголах движения с приставкой про, хотя и употребление бесприставочных глаголов движения возможно:

Когда поезд ехал через туннель, в вагонах включили свет. - Vaghti ghatar az dakhel-e (az miyan-e) (az) tunel harekat mikard, cheragh-ha-ye dakhel-e vagon-ha ra roshan kardand.

Катер долго плыл через пролив, прежде чем вышел в открытое море. - Navche ghabl az inke vared-e darya-ye azad shavad, modat-e tulani az (az dakhel-e) (az miyan-e) natge harkat mikard.

Корабли проплыли через канал и вышли в открытое море. - Keshti-ha az (az dakhel-e) (az miyan-e) kanal ubur kardand va vared-e daryaye azad shodand.

Предлог «через» в сочетании с существительными, демонстрирующими этот специфический характер локумов, соответствует сложным предлогам az dakhel-e, az miyan-e и простому предлогу $a z$. В данной позиции предлоги $a z$, az miyan-e и az dakhel-e в сочетании с локумами могут указывать на направление движения и действия из внутренней части локума к наружной части, то есть в направлении длины локума. В этом значении предлоги $a z$, az dakhel-e и az miyan-e синонимичны.

Также, в этой же ситуации конструкция через + B.n. в сочетании с глаголами с другими приставками и особенно с бесприставочными выражает локум, который может преодолеваться как вдоль, так и поперёк. В этом значении контекст выполняет особую функцию:

Мальчик побежал через переулок к себе домой. - Pesar bache az kuche be samt-e khane david.

Из этого предложения не следует, как мальчик проходил путь - вдоль или поперёк переулка. Если локум преодолевается поперёк, то в данной позиции предлог «через» совпадает с предлогами $a z$ и, точнее, $a z$ arz-e в персидском языке, указывающими на направление движения с одной стороны в другую сторону локума.

2. Предлог «через» в сочетании с существительными, называющими протяжённый локум с линейной особенностью (дорога, улица, переулок, река, тропинка, овраг, долина), выражает перемещение или движение, которое совершается поперёк (с одной стороны локума на другую), а не вдоль локума. Конструкция через + B.n. выражает это значение в сочетании с глаголами с приставкой пере, однако оно возможно и при глаголах с другими приставками, а также при бесприставочных глаголах движения [1, с. 28]:

Мы собрались на лодке переплыть через реку. - Ma tasmim gereftim ba ghayegh az (az arz-e) rudkhane ubur konim.

Из-за машин мы долго не могли перейти через улицу. - Bekhater-e mashin-ha modat-e tulani nemitavanestim $a z$ (az arz-e) khiyaban ubur konim.

Офицер, перегибаясь через стол, что-то говорил даме, держа её тонкую руку. - Afsar ba kham shodan ru-ye miz, dar halike dast-e zarif-e zan ra gereft-e bud, chizi be u goft.

Мальчик бежит через улицу. - Pesar bache az (az arz-e) khiyaban davan davan migozarad.

Из примеров следует, что предлог «через» с этим значением совпадает, прежде всего, с простым предлогом $a z$, а временами и со сложным предлогом $a z$ ru-ye. В этом значении предлог $a z$ обозначает перемещение и движение поперёк локума, а предлог ru-ye - движение и действие контактно по поверхности локума. В персидском языке, чтобы более конкретно уточнить значение перемещения и движения поперёк локума, можно употреблять сложный предлог $a z a r z-e$.

Также, при локумах с линейной особенностью предлог «через» способен передавать движение вдоль всего локума и по всей его протяжённости (из конца в конец). В данной ситуации, локум сопровождается глаголами с приставкой про и бесприставочными глаголами: 
Мы прошли через всю улицу, но аптеки не увидели. - Ma tamam-e khiyaban ra posht-e sar gozashtim, amma darukhane-i nadidim.

Предлог «через» в сочетании с локумами, которые обозначают движение вдоль всего локума и по всей его протяжённости, не переводится на персидский язык, потому что в данной ситуации персидские глаголы являются переходными и требуют послелога $r a$. В данном конкретном случае глагол posht-e sar gozashtan является переходным и употребляется не с предлогом, а с послелогом ra.

3. Предлог «через» может употребляться с локумами с нечёткой, неясной линейной протяжённостью при лимитных или нелимитных плоскостных пространствах (поле, степь, площадка, поляна, сад, лес и т.д.), а также с объёмными частями помещений (комната, кухня, зал). Предлог «через» в сочетании с вышеуказанными локумами обозначает: а) преодоление какого-либо участка локума по удалённой или отделённой от центра части локума, б) пересечение локума через центр, а не по периферии локума. Локум в этом значении употребляется, чаще всего, с глаголами движения с приставкой про, или временами с бесприставочными глаголами. В персидском языке при преодолении и пересечении пути движения через центр предлог «через» выражается сложными предлогами az miyan-e, az vasat-e, az beyn-e и az:

Дети пробежали через сад. - Bache-ha davan davan az miyan-e (az vasat-e) (az beyn-e) (az) bagh gozashtand.

Туристы долго шли через поле. - Turist-ha moddat-e tulani dashtand az miyan-e (az vasat-e) (az beyn-e) (az) keshtzar miraftand.

Мы шли через пшеничное поле. - Ма az miyan-e (az vasat-e) (az beyn-e) (az) gandomzar miraftim.

При преодолении и пересечении какого-либо участка локума по удалённой или отделённой от центра части локума предлог «через» соответствует сложному предлогу az dakhel-e, az miyan-e или простому предлогу $a z$ :

Дети пробежали через сад. - Bache-ha davan davan az miyan-e (az dakhel-e) (az) bagh gozashtand.

Туристы долго шли через поле. - Turist-ha moddat-e tulani dashtand az (az dakhel-e) (az miyan-e) keshtzar miraftand.

Мы шли через пшеничное поле. - Ма az (az dakhel-e) az miyan-e gandomzar miraftim.

В этом значении предлоги az, az dakhel-e и az miyan-e, будучи синонимами, обозначают направление движения и действия с внутренней части локума к наружной, а не по центру.

4. Предлог «через» иногда употребляется в тех случаях, когда локум пересекается и преодолевается для достижения какой-то цели; локумы, указывают на дальнейшую цель движения [1, с. 30]:

Мы шли к метро через парк. - Мa az dakhel-e (az miyan-e) (az rah-e) (az) (az tarigh-e) park be samt-e metro miraftim.

Туристы шли к реке через лес. - Gardeshgar-an az dakhel-e (az miyan-e) (az) (az tarigh-e) (az rah-e) jangal be samt-e rudkhane miraftand.

В этом значении предлог «через» сосредоточивается не на направлении движения по центру, периферии или протяжённости локума, а на преодолении локума для дальнейшей цели движения.

Также, в этом же значении локум может быть населённым пунктом, через который пересекается локум для достижения цели:

Когда ехали через Москву, видели много новых зданий. - Vaghti dashtim az dakhel-e mosko miraftim sakhteman-ha-ye jadid-e ziyadi mididim.

Из Ленинграда в Киев мы ехали через Москву. - Ма az tarigh-e (az rah-e) mosko az leningrad be kiev miraftim.

Поскольку в этом значении предлог «через» сосредоточен не на трассе локума, а только на преодолении локума для дальнейшей цели движения, он передаётся на персидском языке сложными предлогами az-dakhel-e, az miyan-e, az beyn-e, az tarigh-e, az rah-e, а также простым предлогом az. В персидском языке предлоги az tarigh-e и az rah-e более конкретно указывают на преодоление локума для дальнейшей цели движения. 
5. Предлог «через» в сочетании с рядом локумов (пустыня, пески, тайга, заросли колючего кустарника, крапива, болото и т.п.) обозначает в первую очередь преодоление препятствия с физическими трудностями, дискомфортом и неудобством:

Они шли через пустыни, их мучила жажда. Они замерзали в снегах... - Anha az dakhel-e (az miyan-e) (az vasat-e) (az beyn-e) (az) biyaban-ha miraftand, teshnegi anha ra azar midad. Anha dakhele barf-ha yakh zade budand...

Антон сорок дней шёл через пустыню и, наконец, подошёл к прекрасному замку, стоявшему на вершине горы. - Anton chehl ruz az dakhel-e (az miyan-e) (az vasat-e) (az beyn-e) (az) biyaban miraft va saranjam be ghale-i ziba ke bar ru-ye ghole-ye kuh gharar gerefte bud, resid.

Предлог «через» в сочетании с локумами, передающими преодоление препятствия с физическими трудностями, выражается сложными предлогами az dakhel-e, az miyan-e, az vasat-e, az beyn-e, а также простым предлогом $a z$ в персидском языке. Локумы, такие как пустыня, пески, тайга, заросли колючего кустарника, крапива, болото и их персидские корреляты, показывают чаще пространства, которые преодолеваются с физическими трудностями. Предлог «через» и его персидские эквиваленты в сочетании с данными локумами передают семантику преодоления с трудом.

6. Предлог «через» употребляется с вертикальными локумами, которые приходится преодолевать вертикально, поверх их верхней границы (забор, ограда, стена, ворота) [4, с. 305]. Кроме вертикальных локумов, возможно употребление разнообразных барьеров и препятствий, поверх верхней границы которых совершается движение или действие. Также, предлог «через» при вертикальных локумах и разнообразных барьерах и препятствиях обозначает как контактное преодоление препятствия, так и бесконтактное преодоление препятствия (по воздуху):

Ребята забрались в сад через забор. - Bache-ha az ru-ye hesar vared-e bagh shodand.

Ворота были такие высокие, что перелезть через них никто не мог. - Darvaze anghadr boland bud ke hichkas nemitavanest $a z$ ru-ye an be an taraf beravad.

Дети прыгнули через костёр. - Bache-ha az ru-ye (az bala-ye) atash paridand.

Тренер прыгнул через конь. - Morabi az ru-ye (az bala-ye) kharak parid.

Предлог «через» в сочетании с данными локумами соответствует сложным предлогам az ru-ye и az bala-ye в персидском языке. Предлоги az ru-ye и az bala-ye выражают движение или действие, которое совершается по поверхности локума или поверх его верхней границы.

7. Предлог «через» при обозначении проёмов, проходов, вертикальных открывающихся преград (окно, дверь, форточка, проём, калитка, ворота, иллюминатор) передаёт значение «горизонтально пересекать, воспринимать, минуя границу, создаваемую проёмом» [4, с. 305]. Кроме названных локумов, глаголы движения, глаголы преодоления пространства, а также глаголы звукового действия, зрительного и слухового восприятия, выполняют функцию выражения значения предлога «через» в такой ситуации:

Мы вошли в зал через главный вход. - Ма az (az tarigh-e) (az rah-e) vorudi-ye asli vared-e salon shodim.

Татьяна через иллюминатор наблюдала волнующееся море. - Tatiyana az dariche darya-ye mavvaj ra negah mikard.

Через открытое окно доносился запах сирени. - Bu-ye yas az panjare-ye baz be masham miresid.

В персидском языке для выражения предлога «через» в этой ситуации используются простой предлог az и сложные предлоги az tarigh-e и az rah-e, которые указывают на локумы, через которые совершается движение или действие или воспринимается чувство.

8. Предлог «через» может употребляться с существительными, называющими природные возвышенности и вертикальные преграды типа стена, скала, камень, холм, хребет и стекло, обладающие плотной и сплошной средой. Предлог «через» в сочетании с этими существительными и при глаголах движения с приставкой про, глаголах зрительного и слухового восприятия и воздействия, а также глаголах проникать и провалиться обозначает движение и перемещение через тело локума:

Новая автотрасса пройдёт через скалу. - Jadde-ye jadid az (az miyan-e) (az-dakhel-e) sakhre migozarad. 
Звуки не проходят через стены. - Seda-ha az (az dakhel-e) (az miyan-e) divar рад немишаванд.

Лучи солнца проникали через оконное стекло. - Ashaэ-ha-ye khorshid az (azdakhel-e) (az miyan-e) shishe-ye panjare ubur mikard.

Е.Ю. Владимирский выражает такое мнение, что употребление предлога «через» здесь менее предпочтительно и вместо него лучше употреблять предлог сквозь [1]. Предлог «через» с локумами со значением плотной и сплошной среды (стена, скала и т.д.) передаётся на персидский язык простым предлогом az и сложными предлогами az miyan-e и az dakhel-e. Предлоги az miyan-e, az dakhel-e и $a z$ в сочетании с локумами со значением плотной и сплошной среды указывают на локумы, из внутренней части которых проходит трасса, то есть движение через тело предмета.

9. С существительными типа снег, вода, песок, земля, почва, которые обозначают локумы, пропускающие через себя что-либо и обладающие проницаемой средой, может употребляться предлог «через». При таких локумах предлог «через» указывает на путь прохождения внутри пространства. В этом значении предлог «через» употребляется в сочетании с глаголами движения с приставкой про и глаголами проникать, провалиться и прорваться:

Через песок проникала вода. - Ab az dakhel-e (az darun-e) (az miyan-e) (az) mase nofuz mikard.

Речные воды прорываются через замёрзший уже слой грунта. - Ab-ha-ye rudkhane az dakhel-e (az darun-e) (az miyan-e) (az) laye-ye yakh zade-ye khak nofuz mikonand.

В персидском языке для выражения предлога «через» в этой ситуации употребляются простой предлог $a z$ и сложные предлоги az dakhel-e, az darun-e и az miyan-e со значением «из внутренней части», «изнутри» локума.

10. Предлог «через» способен употребляться с локумами типа заросли, огород, чаща, листва, толnа, обозначающими неплотную, несжатую и некомпактную среду, при глаголах движения с приставкой про и глаголы проникать и провалиться:

Кто-то большой, сильный шёл через лес, не разбирая дороги. - Shakhse bozorg va nirumandi bedun-e tavajo be rahash az (az miyan-e) (az dakhel-e) (az rah-e) jangal miraft.

Какой-то верховой продирается через кусты кизила. - Savarei az (az miyan-e) (az dakhel-e) (az rah-e) bute-ha-ye derakht-e zoghal akhte besakhti migozarad.

Эти люди знали, как пролезать через заросли. - In afrad midanestand chetor az (az miyan-e) (az dakhel-e) (az rah-e) butezar ubur konand.

Предлог «через» в сочетании с локумами, описывающими неплотную и несжатую среду, выражается сложными предлогами az miyan-e, az dakhel-e, az rah-e и простым предлогом az. В данной ситуации все указанные персидские предлоги являются синонимами. Предлог «через» и его персидские эквиваленты указывают на направление движения или действия из внутренней стороны, изнутри локума.

11. Предлог «через» употребляется при существительных, выражающих узкие и небольшие в ширине проходы, внутреннюю сквозную пустоту либо прерывность поверхности (щель, отверстие, трещина, дыра) с глаголами зрительного и слухового восприятия и воздействия, а также с глаголами типа пробираться, пробиваться, проникать [1]. В этой ситуации предлог «через» описывает меньшую степень трудности в преодолении препятствующей среды:

Вода проникала через трещины в сосуд. - Ab az dakhel-e (az miyan-e) (az tarigh-e) tarak-ha be dakhel-e zarf nofuz mikard.

Вода проникала сквозь трещины в сосуд. - Ab az labelaye (az la-ye) tarak-ha be dakhel-e zarf nofuz mikard.

Во втором предложении имеются в виду более узкие трещины. В этой ситуации предлог сквозь соответствует персидским предлогам az labelaye и az la-ye. Персидские эквиваленты предлога «через», то есть $a z$ dakhel-e, az miyan-e и az tarighe в сочетании с существительными со значением узких проходов не описывают степень трудности в преодолении препятствующего локума. 


\section{Заключение}

Сравнение системы средств выражения пространственных отношений между персидским и русским языками представляет собой значительные трудности.

В русском языке пространственные значения и средства их выражения (предложно-падежные группы и наречия) многообразны и разнообразны, и, следовательно, основные трудности для иранских обучающихся связаны именно с семантикой и условиями функционирования средств выражения пространственных позиций объекта.

Предлог «через» в сравнении со своими эквивалентными предлогами в персидском языке описывает более конкретно специфику локумов и сред, другими словами, для выражения пространственных отношений с предлогом «через» в русском языке существует богатое разнообразие значений, образующих лексико-грамматическое поле пространственности. В русском языке локумы, употребляемые в конструкции через + B.n., исключительно разнообразны. Разнообразие локумов даёт возможность выразить многообразие значений. Естественно, многообразие значений предлога «через» представляет большие трудности для иранских обучающихся, особенно при переводе с персидского языка на русский, так как в русском языке существуют другие предлоги, выражающиеся эквивалентами предлога «через» в персидском языке. Персидские эквиваленты предлога «через» показали, что чёткая граница среди значений предлогов со значением пространства отсутствует, и для перевода предлога «через» в большинстве ситуаций можно использовать один и тот же предлог. Чтобы избежать вызванных иранскими обучающимися ошибок, выделены семантические компоненты предлога «через» в сочетании с отдельными локумами, а также способы его выражения в персидском языке. Представляется, что наиболее эффективным способом для выделения семантических компонентов предлога «через» с разными локумами является систематизация локумов, которая способствует более глубокому осмыслению данного предлога. Анализ собранных примеров показывает, что предлог «через» может соответствовать разным персидским предлогам, и наиболее употребительными эквивалентами предлога «через» в персидском языке являются предлоги $a z$, az miyan-e и az dakhel-e.

(C) Эстири М., Торкашванд Х., 2021

\section{Список литературы}

1. Владимирский Е.Ю. Выражение пространственных отношений [Электронный pecypc]. -URL: http://journal.pushkin. institute/archive/archive/1979/79-1/ (дата доступа: 09.03.2021)

2. Восканян Г.А. Русско-персидский словарь / Г.А. Восканян. Тегеран: Кухсар, 2003. 830 с.

3. Всеволодова М.В. Способы выражения пространственных отношений в современном русском языке / М.В. Всеволодова, Е.Ю. Владимирский. Москва: Книжный дом «ЛИБРОКОМ», 2009. 288 с.

4. Книга о грамматике / под ред. А.В. Величко. СПб: Златоуст, 2018. 752 с.

5. Лагута Н.В. Изучение пространственных предлогов на занятиях по русскому языку как иностранному [Электронный pecypc]. -URL: https://cyberleninka.ru/journal/n/slovo-folklorno-dialektologicheskiy-almanah?i=901199

6. Овчинникова И.К. Русско-персидский словарь / И.К. Овчинникова, Г.А. Фуругян, Ш.М. Бади. Тегеран: Изд-во Джаведан-е Херад, 2009. 1092 с.

7. Рубинчик Ю.А. Грамматика современного персидского литературного языка / Ю.А. Рубинчик. Москва: Восточная литература, 2001. 600 с.

8. Словарь русского языка в четырёх томах, Т. 4 (с-я) / под ред. А.П. Евгеньевой. Москва: Русский язык, 1988. 800 с.

9. Словарь современного русского литературного языка, Т. 17 (х-я) / под редакцией Л.С. Ковтун, В.П. Петушков. Москва, Ленинград: Наука, 1965. 2126 с.

10. Яо Цзяжу. Средства выражения пространственных значений в русском и китайском языках (лингводидактический аспект) // Вестник РУДН: серия Русский и иностранные языки и методика их преподавания, Москва: Российский университет дружбы народов, 2016. С. 150-155.

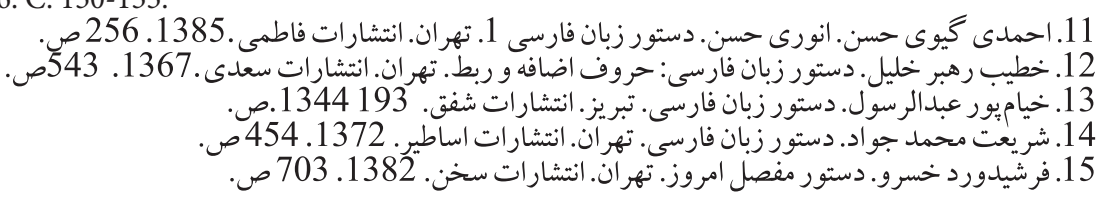




\section{References}

1. Vladimirskii, E.Iu. Vyrazhenie prostranstvennykh otnoshenii [Expressing spatial relations], journal.pushkin.institute/archive/ archive/1979/79-1/ (accessed: 09.03.2021)

2. Voskanian, G.A. Russko-persidskii slovar'[Russian-Persian Dictionary] / G.A. Voskanian. Tegeran: Kuhsar, $2003.830 \mathrm{~s}$.

3. Vsevolodova, M.V. Sposoby vyrazheniia prostranstvennykh otnoshenii v sovremennom russkom iazyke [Ways of expressing spatial relations in modern Russian] / M.V. Vsevolodova, E.Iu. Vladimirskii. Moskva: Knizhnyi dom «LIBROKOM», 2009. $288 \mathrm{~s}$.

4. Kniga o grammatike [A book about grammar] / pod red. A.V. Velichko. SPb: Zlatoust, 2018. $752 \mathrm{~s}$.

5. Laguta, N.V. Izuchenie prostranstvennykh predlogov na zaniatiiakh po russkomu iazyku kak inostrannomu [The study of spatial prepositions in Russian language as a foreign language], cyberleninka.ru/journal/n/slovo-folklorno-dialektologicheskiyalmanah?i=901199

6. Ovchinnikova, I.K. Russko-persidskii slovar'[Russian-Persian Dictionary] / I.K. Ovchinnikova, G.A. Furugian, Sh. M. Badi. Tegeran: Izd-vo Javedan-e Kherad, 2009. $1092 \mathrm{s.}$

7. Rubinchik, Iu.A. Grammatika sovremennogo persidskogo literaturnogo iazyka [Grammar of modern persian literary language] / Iu.A. Rubinchik. Moskva: Vostochnaia literatura, 2001. 600 s.

8. Slovar'russkogo iazyka $v$ chetyrekh tomakh, T. 4 (s-ia) [Dictionary of the Russian language in four volumes, V. 4 (s-ia)] / pod red. A.P. Evgenevoi. Moskva: Russkii iazyk, 1988. 800 s.

9. Slovar'sovremennogo russkogo literaturnogo iazyka, T. 17 (kh-ia) [Dictionary of modern Russian literary language, V. 17 (khia)] / pod redaktsiei L.S. Kovtun, V.P. Petushkov. Moskva, Leningrad: Nauka, 1965. 2126 s.

10. Iao Tsziazhu. Sredstva vyrazheniia prostranstvennykh znachenii v russkom i kitaiskom iazykakh (lingvodidakticheskii aspect) [Methods of expressing spatial meanings in Russian and Chinese languages (linguistic and didactic aspect)] // Vestnik RUDN: seriia Russkii i inostrannye iazyki i metodika ikh prepodovaniia, Moskva: Rossiiskii universitet druzhby narodov, 2016. S. 150155.

11. Ahmadi-Givi Hasan. Anvari Hasan. Dasture zabane farsi 1 [Persian grammar 1]. Tehran. Entesharate Fatemi [Fatemi Publication]. 1385. $256 \mathrm{~s}$.

12. Khatib-Rahbar Khalil. Dasture zabane farsi: horufe ezafe va rabt. [Persian grammar: prepositions and conjunctions]. Tehran. Entesharate Saadi [Saadi Publication]. 1367. 543 s.

13. Khaiampur Abdo-Alrasoul. Dasture zabane farsi [Persian grammar]. Tabriz. Entesharate Shafagh [Shafagh Publication]. 1344. $193 \mathrm{~s}$.

14. Shariat Mohammad-Javad. Dasture zabane farsi [Persian grammar]. Tehran. Entesharate Asatir [Asatir Publication]. 1372. 454 s.

15. Farshidvard Khosro. Dasture mofassale emruz [Contemporary detailed grammar]. Tehran. Entesharate Sokhan [Sokhan Publication]. 1382. $703 \mathrm{~s}$.

\section{Сведения об авторах:}

Маджид Эстири - кандидат филологических наук, ассистент профессора, преподаватель кафедры иностранных языков университета Гонбад-Кавус (Иран). Сфера научных и профессиональных интересов: сравнительная грамматика (русского и персидского языков), лингвострановедение, лингвокультурология, перевод. E-mail: estiri@mail.ru

Хосро Торкашванд - кандидат филологических наук, ассистент профессора, преподаватель кафедры иностранных языков университета Гонбад-Кавус (Иран). Сфера научных и профессиональных интересов: сравнительная грамматика (русского и персидского языков), лингвострановедение, лингвокультурология, перевод. E-mail: khosro@mail.ru

\section{About the authors:}

Majid Estiri - Candidate of Philology, Assistant Professor, Lecturer at the Department of Foreign Languages of the University Gonbad Kavous (Iran). Research and professional interests: comparative grammar (Russian and Persian), linguistic and cultural studies, cultural linguistics, translation. E-mail: estiri@mail.ru

Khosro Torkashvand - Candidate of Philology, Assistant Professor, Lecturer at the Department of Foreign Languages of the University Gonbad Kavous (Iran). Research and professional interests: comparative grammar (Russian and Persian), linguistic and cultural studies, cultural linguistics, translation. E-mail: khosro@mail.ru 